\title{
Literatura erótica em blogs: análise do universo feminino nos blogs de literatura erótica ${ }^{1}$
}

\author{
Maitê Celly da Silva Gomes \\ Bacharel em Biblioteconomia pela Universidade Federal do Rio Grande do Norte \\ E-mail: maitecsgomes@gmail.com \\ Luciana Moreira Carvalho \\ Doutora em Ciência da Informação pela Universidade do Porto, Portugal \\ Professora adjunta do Departamento de Ciência da Informação da UFRN \\ E-mail: luciana.moreeira@hotmail.com
}

\begin{abstract}
RESUMO:
Trata de uma pesquisa cujo objetivo foi analisar o universo feminino nos blogs de literatura erótica. No percurso metodológico, utiliza-se o método qualitativo de estudo de caso, com técnicas de observação direta de cinco blogs de literatura erótica, a partir das seguintes categorias: arquitetura da página, layout, atualizações, acessibilidade, visitas, número de seguidores, gênero do autor, postagens, comentários e o feedback dos blogueiros. A partir dos blogs analisados, foi possível perceber como esses se desenvolvem no dia a dia em relação as postagens, aos blogueiros e aos usuários. $\mathrm{A}$ maioria dos blogs apresentam uma boa arquitetura, um layout atrativo e atualizações constantes. Os blogs são escritos em sua maioria por mulheres e tem um público majoritariamente feminino, que utiliza o espaço para compartilhar experiências de relacionamentos, além de discutir e divulgar a literatura erótica. Conclui-se que esses blogs são excelentes fontes de informação ao público adepto, pois tem um direcionamento aberto e sem preconceitos.
\end{abstract}

Palavras-chave: Literatura erótica - blogs. Fontes de informação - blogs. Universo feminino.

\section{ABSTRACT:}

It deals with a research whose objective was to analyze the feminine universe in the blogs of erotic literature. In the methodological course, the qualitative method of case study, using techniques of direct observation of five blogs of erotic literature, is used, from the following categories: page architecture, layout, updates, accessibility, visits, number of followers, gender The author, posts, comments and feedback from bloggers. From the blogs analyzed, it was possible to see how they develop in the day to day in relation to the posts, bloggers and users. Most blogs feature good architecture, an attractive layout and constant updates. The blogs are written mostly by women and have a mostly female audience, who use the space to share experiences of relationships, as well as discuss and disseminate erotic literature. It concludes that these blogs are excellent sources of information to the adept public, since it has an open and unbiased direction.

Keywords: Erotic literature - blogs. Information Sources - blogs. Feminine Universe.

\footnotetext{
${ }^{1}$ Este artigo apresenta parte dos resultados da monografia de final do curso de Graduação em Biblioteconomia, da Universidade Federal do Rio Grande do Norte.
} 


\section{INTRODUÇÃO}

Existem mitos e preconceitos quando se trata de literatura erótica. Necessitamos de uma visão crítica e consciente relacionada ao assunto. Atualmente com o avanço tecnológico, existem diversos suportes informacionais para a disseminação desse gênero literário que muitas vezes é confundida com literatura pornográfica. Esses dois gêneros literários têm suas semelhanças e particularidades, a literatura erótica é baseada no amor e nas suas inspirações, manifestando-se em forma de palavras, imagens e sentimentos de desejos que possam estimular o desejo sexual. Enquanto que a literatura pornográfica tem um apelo totalmente sexual e explícito.

Na década de 1960, ocorreram muitas novidades tecnológicas como o advento da internet e a utilização de técnicas literárias, gerando discursos e debates sobre tais assuntos.

$\mathrm{Na}$ atualidade o cenário imaginário encontra-se um pouco mais liberal, pois com o acesso as tecnologias e as novas fontes de informação, como os blogs, a acessibilidade e usabilidade desse gênero literário encontram-se a disposição de quem desejar.

Os blogs surgiram como um diário íntimo na internet, com o objetivo de compartilhamento de informações pessoais com seus leitores, com o propósito de estabelecer um diálogo entre o diarista (blogueiro) e o leitor (usuário).

A partir do universo dos blogs, observou-se uma lacuna em relação à pesquisas sobre o tema específico da literatura erótica, estabelecendo-se, portanto, como objetivo, analisar o universo feminino nos blogs de literatura erótica. Para tanto se fez necessário a pesquisa bibliográfica, com o estudo de caso e a utilização da técnica de observação para a coleta de dados nos blogs especializados nesta temática.

No percurso metodológico, foram utilizados os seguintes procedimentos: quanto à abordagem a pesquisa é teórica e empírica por aliar a teoria e a prática, e é qualitativa pela forma de descrever os resultados. Para a coleta de dados foi necessária a utilização da técnica de observação. Quanto aos objetivos é descritiva e quanto a coleta de dados a pesquisa se desenvolve de forma bibliográfica, pois utilizou-se de livros, periódicos e artigos. Pode-se enquadrá-la como um estudo de caso já que necessitou de um ambiente específico para a realização da pesquisa, 
sendo, para a realização da mesma o ambiente virtual. A amostra contou com cinco blogs pesquisados, que foram selecionados a partir do conhecimento prévio da pesquisadora como usuária/interlocutora nesses blogs.

A seguir serão apresentadas sessões para um suporte teórico para um melhor entendimento relacionado ao tema, colaborando com a quebra do tabu que circunda o erotismo e finalizando com os resultados da nossa pesquisa.

\section{LITERATURA ERÓTICA: RESUMO HISTÓRICO}

A literatura erótica é um gênero que inclui toda literatura licenciosa (sensual), direcionada exclusivamente ao desejo sexual e ao amor. O erotismo utilizado na literatura não pode ter seus conceitos reduzidos pela sua natureza polêmica e também por fazer parte de preconceitos, tabus e das obscenidades humanas como orgias e fetiches. Há quem pense, que esse gênero literário reflete de forma negativa na formação moral dos jovens, e que a igreja foi o seu principal combatente. Com o cristianismo consolidado em Roma, este não conseguiu abolir o fim da tradição da literatura erótica. Alexandrian (1993) mostra que esta imposição não era só das igrejas, mas também de pensadores e filósofos que queriam manter a ordem e a decência quando afirma:

\footnotetext{
Um preconceito arraigado é acreditar que o cristianismo foi o inimigo da literatura, enquanto o paganismo teria sido seu defensor incondicional. $\mathrm{Na}$ realidade não foram os pais da igreja, mas os filósofos estóicos como Sêneca que começaram a chamar os órgãos genitais de 'partes vergonhosas' ou pundela (os gregos diriam aidofa).
}

Os gregos foram os primeiros a se sobressaírem em relação aos temas sexuais e eróticos na literatura. Para Alexandrian (1993, p.18) Meleagro é "o melhor poeta erótico grego da antiguidade, fremente, fervente de ardor sexual". O autor também cita Alcman como o inventor das canções eróticas. Aristófanes nascido por volta de 446 a. C. em Atenas foi o único que teve suas obras completas e não danificadas até a atualidade, onde mostram cenas e diálogos obscenos, em que se destacam duas peças geniais, Lisístrada considerada a obra prima do erotismo antigo e $A$ assembleia das mulheres.

Em Roma, assim como para os gregos, surge a literatura erótica através do estilo do texto em diálogos licenciosos. Alexandrian (1993), afirma que, o erotismo latino clássico aparece no período em que a civilização romana está mais evoluída e 
requintada e não expressava a sexualidade de forma tão explicita como Aristófanes expressava em sua peça Lisístrada.

Os clássicos do erotismo latino surgiram no período do imperador Augusto. De acordo com Alexandrian (1993), Horácio foi o poeta oficial desse imperador. O autor classifica Catulo como o primeiro poeta latino erótico.

Petrônio também foi uma figura importante para a literatura erótica latina, muito admirado pelo imperador Nero, deixando sua marca na literatura como o livro Satyricon, que segundo Alexandrian (1993, p.28, grifo do autor): "De fato, a obra Satyricon é sobretudo uma obra de esteta, com trechos paródicos ou voluntariamente exagerados[...]".

Alexandrian (1993) afirma que o primeiro livro erótico do século XIX, foi publicado em 1800 clandestinamente e intitulado L'Enfant du bordel do escritor Charles Pigault Lebrun, admirado por Napoleão e seu irmão Jerônimo.

$\mathrm{Na}$ idade média surge o conceito de luxúria, considerado pela igreja católica um dos pecados capitais, que afastavam o homem cada vez mais do reino de Deus. Enquanto que as mulheres eram consideradas moedas de troca, e após o casamento eram totalmente submissas aos seus maridos. Para o autor supracitado, Eustache Deschamps foi o primeiro poeta erótico francês e se destacou pelas peças eróticas que misturavam malícia e obscenidade.

No século XIV, dar-se a finalização da idade média para o início do renascimento, com Giovanni Boccaccio que produziu novelas licenciosas compondo o livro Decameron, classificado por modificar a literatura licenciosa ingênua e brutal em um erotismo refinado. Além desse autor, outro que destacamos é Gianfrancesco Poggio Straparola que foi o primeiro escritor de literatura erótica do renascimento, com o livro Noites faceciosas (1550). Esta obra ao contrário de Decameron foi condenada e inscrita no Índex de livros proibidos, devido as suas anedotas sexuais em 1624.

No renascimento a Itália tornou-se o centro onde a literatura erótica se requintou, onde se enriqueceu de temas e formas que influenciaram os outros autores ocidentais. O Decameron abrira o caminho por onde enveredam novelistas que ampliaram o repertório dos antigos contos milésimos e neles introduziram uma graça particular. Descobriu-se que a descrição das relações sexuais não era incompatível com a bela linguagem, mas metáforas amáveis, a elegância dos personagens, a alegria saudável. (ALEXANDRIAN, 1993, p.61, grifo do autor) 
Para Alexandrian, os escritos licenciosos franceses alcançaram os escritos italianos na segunda metade do século XVI. O último livro inscrito na Renascença francesa foi Le Moyen de parvenir de Béroalde de Verville, considerado por Alexandrian (1993, p.114): "o lance mais alto de todo o humanismo licencioso do século precedente".

No início do século XIX ao século XX, o erotismo é cultivado por diversos escritores, que recorreram a literatura erótica para aguçar os sentidos mais íntimos de seus leitores, proporcionando uma vitalidade que não é encontrada em outros tipos de narrativa. Em destaque, podemos citar alguns autores que não só apreciam mas incentivam a leitura desse gênero literário, são eles: Carlos Drummond de Andrade, Machado de Assis, Gilberto Freyre, Marquês de Sade, Safo, Hilda Hilst, George Sand, Oscar Wilde, G. Bataille, D. H. Lawrence, entre outros.

Nessa literatura também podemos ver algumas questões de gênero, e se engana quem pensa que esta questão é atual. Ao contrário, vem de séculos atrás, assim, como a homossexualidade, o amor entre indivíduos do mesmo sexo e a aceitação de gênero, ou seja, o que define a sexualidade do ser humano não são seus órgãos genitais e sim o que se desenvolveu no seu subconsciente, no seu interior e a sua aceitação.

A literatura homo afetiva teve sua aceitação na Europa e principalmente na França, onde seus autores contam seus amores sodomitas (atos sexuais obscenos praticados pelos cidadãos da cidade de Sodoma) de forma inocente. Podemos ver algumas passagens homossexuais no livro de Alexandrian (1993) intitulado a história da literatura erótica, nos capítulos 9 (Os companheiros de Sodoma) e no capítulo 10 (O erotismo surrealista), onde ele apresenta de maneira clara o relacionamento amoroso entre homens e mulheres com parceiros (a) do mesmo sexo.

Com passagens eróticas dentro dos romances, os leitores utilizaram-se dessa literatura para despertar a imaginação, assim podendo apreciar a literatura erótica sem ter que se justificar para outras pessoas, sem risco de sofrer preconceitos ou julgamentos da outra parte.

Em 1920, surgem os primeiros quadrinhos eróticos ou pornográficos como eram considerados nos EUA. Eles eram compostos de muito humor e com personagens bastantes conhecidos pelas crianças como: Mickey Mouse, Betty Boop e Popeye. No século XX surge o mutescope ${ }^{2}$. Através deste era possível pequenas

\footnotetext{
2 Projetor com manivela.
} 
animações e estas exibiam pequenas imagens de mulheres tirando a roupa. Também não podemos esquecer do jornal Rio Nu, criado em 1900 que circulou na capital da República até 1916. Este jornal era carregado de piadas maliciosas, poemas e canções de duplo sentido, continham charges de histórias apimentadas, a linguagem era ultra livre e tinham gravuras de cenas de amor para todos os paladares. Para Del Priore (2014),

As primeiras revistas de nus feminino apareceram na França e continham imagens de artistas - em sua maioria saídas do teatro burlesco e de bordéis que eram usadas como modelos. Elas posavam nuas ou seminuas no interior das páginas ou nas capas. (DEL PRIORE, 2014, p.130)

Era através destes suportes que a literatura erótica se disseminava, chegando assim ao conhecimento de muitos usuários adeptos, que se interessavam por este estilo de gênero para diversão, curiosidade ou informação.

Para Alexandrian (1993), a literatura erótica feminina tem origens imprecisas e um desenvolvimento tardio. Foram produzidas obras interessantes, mas nenhuma considerada obra prima. O autor relacionou essa observação à própria natureza erótica da mulher, que pode experimentar sensações sexuais mais profundas que os homens.

Há poucos relatos de mulheres que se aventuraram na escrita deste gênero literário, pois elas não tinham liberdade de expressão, nem o direito à educação. Foi no período medieval e renascentista que algumas mulheres desafiaram a repressão e escreveram sobre o erotismo, sendo algumas ameaçadas e torturadas. Na Grécia antiga, foram atribuídos os primeiros textos eróticos femininos.

De acordo com Alexandrian (1993), poucas foram as mulheres que tiveram a oportunidade de ter acesso à educação e a cultura, enveredando-se pelo caminho da literatura e deixando alguns escritos muito significativos relacionados ao erotismo/romance/sentimento, considerados inadequados para aquela época, como exemplo de mulheres que deixaram sua contribuição para essa literatura podemos citar: Marie de France e a rainha Elizabeth I.

Segundo o mesmo autor, Safo foi considerada a primeira poetisa erótica da Antiguidade. No Renascimento, houve cortesãs que escreveram alguns livros que celebravam o amor platônico, entre elas podemos citar: Tullia d'Aragona em seu Dialogo dela infinita di amore (1547), Jeanne Flore com Contes amoreux (1543), Prenette du Guillet em Rymes (1545) e por fim, Louise Labé foi a única escritora que 
descreveu o amor como uma sensação física. No entanto, para Alexandrian (1993, p.20) "A primeira romancista original da literatura erótica foi a marquesa de Mannoury d'Ectoc [...]".

Atualmente podemos dizer que a mulher ainda é taxada como estereótipo sexual, mas isso não faz delas um objeto. Este papel se dá devido ao machismo e preconceito que continuam fazendo parte da sociedade, sendo considerado cultural. Os homens quando expressam o amor e pensamentos sensuais são aplaudidos pela sociedade, enquanto que as mulheres ao fazerem o mesmo são julgadas e censuradas.

Para Alexandrian (1993) "A literatura feminista moderna criticou a questão sexual, mas muitas vezes dando prova de um obscurantismo desolador". Essa literatura não tem origens precisas e se desenvolveu tardiamente. Além disso, não se pode negar as diferenças entre homens e mulheres, mas em contrapartida, elas queriam mostrar a indignação através da literatura feminista, que não aceitava que a mulher fosse mostrada como inferior. Alexandrian (1993, p.323) diz que

\footnotetext{
A partir daí algumas mulheres de letras empreenderam a crítica do 'discurso masculino'. Tratava-se de demonstrar que em todas as épocas o homem fora um tirano pavoroso que não entendia nada desse diamante sem defeito que era a mulher.
}

Foi uma grande e especial conquista para as mulheres poder expressar na literatura seus pensamentos, desejos e exigências internas do seu corpo de forma escrita, sem hipocrisia e com o naturalismo essencial e insuperável.

\section{LITERATURA ERÓTICA EM BLOGS}

Através da internet, a disseminação da informação expandiu-se de forma exponencial; com isso, viu-se a possibilidade de criar meios e de divulgar as informações de formas variadas, possibilitando o acesso aos usuários sem que fosse preciso custo com materiais físicos para a abrangência de criação de novos conhecimentos. Essa mesma internet proporcionou aos cidadãos um poder de supervisionar, analisar e divulgar informações sem que este usuário seja um profissional da informação. Um exemplo desses novos espaços pode ser representado pelo blog, que possibilita não só a leitura, mas a troca de informações à 
respeito do tema desejado, já que procuramos meios cada vez mais fáceis e adequados para a nossa comunicação. Para Hewitt (2007, p.14)

[...] milhões de pessoas estão, mais uma vez, mudando seus hábitos no que diz respeito a informação. Sim, pois isso aconteceu muitas vezes antes: com o aparecimento da imprensa, depois do telégrafo, do telefone, do rádio, da televisão e da internet.

Com os avanços tecnológicos e consequentemente da internet, os meios de comunicação foram evoluindo através de máquinas produzidas pelo homem, codificadas e transformadas em informação e comunicação produzindo lucros, transformando as organizações e mostrando ao público suas qualidades, diversificações de produtos e serviços existentes.

De acordo com Hewitt (2007), hoje já existem mais de quatro milhões de blogs circulando por toda a rede virtual. A febre do blog iniciou quando os blogueiros começaram a cria-los tratando de assuntos diversos. Algumas pessoas utilizavam como um diário virtual e, outros, utilizavam para falar sobre moda, organização, literatura, design, política entre outros. Isso porque os blogueiros sabiam da importância e o interesse dos internautas por notícias divulgadas nestes.

\begin{abstract}
O surgimento dos blogs trouxe uma nova revolução já criada pela internet. É provável que boa parte do sucesso dos movimentos dos blogs esteja justamente no resgate das ideias expressas por meio do texto, quebrando a maré da supervalorização do design da web comercial. O casamento não poderia ter sido mais feliz - a velocidade e a onipresença da internet com a volta à troca livre de ideias, sem compromisso com técnica de design e sem que tenha que aprender coisa alguma, além de acessar um provedor e manejar um mouse. (SILVA, 2005, p.167)
\end{abstract}

Esta é uma nova transformação em relação a mais uma mudança de hábito da sociedade, na comunicação e na maneira de escrever e disponibilizar o conteúdo de forma pública e não privada. O blogé a abreviatura de "web" mais "log", que deriva de "login", e é uma espécie de diário pessoal e virtual, diferentemente do diário físico, que é de acesso privado. Para a comunidade de blogs não ficar dispersa, foi criado a blogosfera que representa o mundo dos blogs, ou a comunidade destes.

Segundo Schittine (2004, p.162): "O blog é, de fato, uma mídia independente das grandes corporações, mas que reclama um espaço nelas". Foi neste período que os blogs se tornaram um dos sistemas mais utilizados da internet. Com esta procura, muitas empresas traduziram seus sistemas de blogs para a língua portuguesa a fim 
de uma melhor interação com o público brasileiro. Essa ferramenta de interação, transformou os blogueiros em escritores também, já que estes participam de forma direta escrevendo nos blogs, realizando comentários, críticas, opiniões desde coisas mais simples até as mais relevantes.

Os blogs são frequentemente atualizados, pois seus administradores (blogueiros) alimentam com informações pertinentes ao tema exposto para que seus usuários possam acessar, acompanhar e realizar comentários relacionados ao tema, como se fossem uma espécie de bate papo virtual em que o blogueiro alimenta com uma informação, o usuário lê e coloca suas observações ou críticas e, muitas vezes tem um feedback do administrador do blog. Nestes, existem alguns links para a web, onde o usuário pode pesquisar e analisar sobre o assunto, sem que haja a necessidade de abrir outras páginas e continuar a sua busca pela informação desejada. Nesse contexto, podemos afirmar que tanto os blogs, como os websites são considerados depósitos de informações da nossa atualidade e responsáveis por muitas mudanças ocorridas na política e na sociedade.

Podemos dizer que o blogé uma rede interativa na qual através de um espaço virtual entre o blogueiro (autor) e o usuário (leitor) trocam ideias, essas informações vão sendo expandidas pelas vias de comunicação, gerando novas informações e novos conhecimentos. Segundo Chaguri, Bertolleti e Azevedo (2009) "[...] Blogs são páginas de Internet que são atualizadas com frequência e seus conteúdos dependem unicamente do que o autor desejar publicar".

Quando acessamos especificamente blogs com conteúdo eróticos, temos acesso também a algumas comunidades de literaturas românticas, que em meio ao seu conteúdo encontraremos cenas eróticas. Nessas comunidades, é possível ver propagandas das obras feitas pelos próprios autores, que descrevem o tema, nos proporcionando curiosidade e consequentemente o desejo de ler. Podemos encontrar comunidades como: Romance Writers and Readers, Love and Romance, Romance Readers, entre outros. As possibilidades e escolhas pelas comunidades são variadas já que existem diversas delas para todos os públicos. Desde os mais jovens até os adultos com conteúdo direcionados para maiores de 18 anos.

Os blogs de literatura erótica são de fácil acesso, e a comunicação entre blogueiros e seguidores é rápida e interativa. A colaboração e a participação são fundamentais para o sucesso de um blog, pois quanto mais atualizado, melhor se torna 
a procura, tornando um ambiente virtual interessante, expressivo e bastante frequentado pela comunidade que a segue.

Esta ferramenta têm uma linguagem clara e direta, mostrando imagens das capas dos livros, os resumos, os prólogos e os epílogos. É comum trazerem comentários e dicas relacionadas às histórias, mostrando o grau de erotismo que cada uma contém.

Podemos inferir que os blogs como fonte de informação de acesso livre através da internet, tem influenciado o universo feminino, através da disseminação de conteúdos eróticos. Mostrando, assim, que a mulher é muito mais importante do que um simples objeto de prazer, com respeito, com sua beleza, com sua inteligência, mas principalmente com a sua força e luta pela mudança.

\subsection{O UNIVERSO FEMININO NOS BLOGSDE LITERATURA ERÓTICA}

O erotismo feminino e a literatura erótica cresceram devido ao avanço tecnológico através dos blogs, chats, sites entre outros. Desde o início da escrita da literatura erótica, os homens sempre dominaram o público adepto. Antigamente, como já mencionado, as mulheres não podiam ler nem escrever histórias ousadas. Hoje, temos várias opções de histórias ousadas e de diversos estilos.

Os livros voltados ao público feminino são mais recentes e tem uma boa aceitação, isso se deve ao apelo que estas histórias tem entre as mulheres. A indústria de entretenimento está aí para ambos os sexos.

A expressão de erotismo apresentadas na literatura é privilégio dos homens e não das mulheres, isso porque o objeto erótico que atrai a atenção dos homens é o estereótipo de mulher, sempre linda, arrumada e provocante, excitando e atraindo a atenção masculina; sempre representando o homem como o sujeito e a mulher como o objeto. Segundo Schittine (2004, p.103, grifo do autor)

\footnotetext{
O erotismo, o exibicionismo, a intimidade escancarada, impudica, ou mesmo a intimidade naive dos problemas amorosos das mulheres fizeram aflorar no espaço público e unissex da internet um discurso íntimo e feminino. Um discurso que passa das páginas das revistas femininas para o diário íntimo exposto em rede.
}

Existem alguns blogs na internet que discutem sobre os problemas, ou seja, as mudanças no corpo, a incompreensão dos homens e a criatividade feminina, 
expondo uma explosão de informações e ideias. Há um grupo de mulheres disposta a divulgar e tratar de temas polêmicos, mas interessantes, que afloram os sentidos e as curiosidades de ambos os sexos como Schittine (2004, p.102) relata que

O blog Delícias cremosas (www.deliciascremosas.blogspot.com) reúne um grupo de 13 mulheres - do Rio de Janeiro, Recife, Porto Alegre e São Paulo que contam as suas mais profundas intimidades, conquistas e aventuras sexuais em rede.

O compromisso dessas blogueiras com o leitor é realizar comentários e discussões no campo íntimo/sexual, como confidências, comportamentos na cama, fetiches, etc. As próprias autoras do blog acrescentam que o "Delícias cremosas" não é um site pornográfico, são mulheres falando das suas experiências de vida sem pudores e sem meias palavras.

Ao longo das gerações tem ocorrido muitas mudanças, pois transformações sociais ocorrem com diferentes costumes e conceitos em relação ao feminino. Para João $(1997$, p.57)

A mulher esteve confinada dentro do lar há milênios, sendo encarregada dos chamados trabalhos domésticos, acumulando, também, essas funções de esposa e mãe. $O$ fato dela vir a deixar essas funções era visto com certa apreensão, pois, com certeza, teriam que ser substituídas pelas extradomésticas.

Uma dessas mudanças ocorridas foi na escrita, quando estas conquistaram a liberdade de escrever e expressar seus pensamentos e desejos. Também a conquista pelo direito do voto, a profissionalização, sendo uma das maiores conquistas alcançadas, com o ingresso nas universidades, entre outras.

Nesse espaço que chamamos de "universo feminino" nos blogs, encontramos, além de resenhas e livros literários, dicas de beleza, de maquiagens, filmes, contos eróticos, fantasias sexuais, entre outros. Mostrando um repertório rico em diversos tipos de informação, transmitidas em grande parte por mulheres dispostas a apresentar essas informações sem pudor e sem receio de serem subjugadas por seus comentários explícitos e em algumas vezes ilícitos, dependendo da forma que são interpretadas.

Em uma sociedade onde rotular e padronizar tudo parece ser a solução, as mulheres são cobradas cada vez mais, tudo por conta do machismo institucionalizado que as pressionam, exigindo sempre um corpo belo, uma aparência deslumbrante e diferenciada. Ou seja, um estereótipo convidativo para o sexo. 


\section{ANÁLISE E DISCURSSÃO DOS RESULTADOS}

A partir do objetivo de analisar o universo feminino nos blogs de literatura erótica, traremos agora os resultados desta pesquisa, aqui apresentados de forma sintetizada, com os pontos mais relevantes de todo o processo. Para uma melhor compreensão, elaborou-se um quadro, constando as categorias de análise da pesquisa, são elas: arquitetura, layout, atualizações, acessibilidade, visitas, seguidores, gênero do autor, postagens, comentários e o feedback dos blogueiros, observando o comportamento de ambos, relacionados aos blogs de literatura romance/erótica.

Os blogs analisados foram: a) papo de homem (criado em 2016, para tratar de assuntos de homens que normalmente não são conversados. Começou como um blog e virou um site devido à enorme proporção que tomou no decorrer dos tempos. Hoje é composto por 15 funcionários que propagam informações (artigos) diversos. Inclusive livros de literatura erótica, com divulgações e comentários relacionados ao erotismo); b) adoramos romances em e-book (criado por Rozi Franzin e composto por 2.374 seguidores do blog e 389 leitoras no Google +); c) romances em e-book históricos (sua autora é a blogueira Genna Jen. Nele, encontramos slides das capas dos livros, as resenhas, o número de seguidores, as fotos de alguns seguidores, biblioteca, janela para pesquisa, indicações de livros como os lançamentos, Iguns autores inclusive brasileiros, últimos comentários, postagens populares, músicas entre outros); d) livro e contos-literatura erótica (tem como autores as blogueiras Josi Novaes (baiana e estudante de pedagogia) e Gisele Lino (baiana e técnica de enfermagem). Elas postam novelas literárias, capítulos de livros (muitas vezes escritos por elas mesmas, para o blog), séries, contos entre outros); e) sempre romântica (tem como autora a blogueira Leninha, que posta informações pertinentes ao assunto).

Através das observações realizadas, foi possivel verificar as informações extraídas desses blogs. Conforme o quadro elaborado, a partir das categorias de análises, foi possível perceber como esses blogs se desenvolvem no dia a dia em relação as postagens, aos blogueiros e aos usuários. 
Quadro 1 - Categoria de análise dos blogs

\begin{tabular}{|c|c|c|c|c|c|}
\hline \multirow[b]{2}{*}{ CATEGORIAS } & \multicolumn{5}{|c|}{ BLOGS } \\
\hline & PAPO DE HOMEM & $\begin{array}{l}\text { ROMANCE EM } \\
\text { EBOOK }\end{array}$ & $\begin{array}{c}\text { EBOOK ROMANCES } \\
\text { HISTORICOS }\end{array}$ & $\begin{array}{l}\text { LIVROS E CONTOS - } \\
\text { LIT. ERÓTICA }\end{array}$ & $\begin{array}{c}\text { SEMPRE } \\
\text { ROMÂNTICA }\end{array}$ \\
\hline Arquitetura & Simples & Simples & Simples & Complexa & Simples \\
\hline Layout & Insatisfatório & Satisfatório & Satisfatório & Insatisfatório & Satisfatório \\
\hline Atualização & Atualizado & Atualizado & Atualizado & Desatualizado & Atualizado \\
\hline Assuntos & $\begin{array}{l}\text { Especialmente conversas } \\
\text { de homem }\end{array}$ & $\begin{array}{c}\text { Histórias de romance/ } \\
\text { Erótico }\end{array}$ & $\begin{array}{c}\text { Romances/ } \\
\text { Eróticos históricos }\end{array}$ & $\begin{array}{l}\text { Romances/ Eróticos } \\
\text { históricos }\end{array}$ & Romances \\
\hline Acessibilidade & Não & Não & Não & Não & Não \\
\hline Visitação & Não mostra & $8.443,200$ & $4.526,865$ & 53.349 & $5.907,915$ \\
\hline Seguidores & Não mostra & 2.373 & 3.911 & 55 & 5.835 \\
\hline Gênero do autor & Masculino & Feminino & Feminino & Feminino & Feminino \\
\hline Postagens & Artigos variados & $\begin{array}{l}\text { Resenhas de livros, } \\
\text { indicação de outras histórias, } \\
\text { próximos lançamentos. }\end{array}$ & $\begin{array}{l}\text { Resenhas de livros, trechos } \\
\text { de capítulos dos livros, } \\
\text { indicação de outros livros. }\end{array}$ & Resenhas dos livros. & $\begin{array}{c}\text { Resenhas dos livros, dicas } \\
\text { de leitura, etc. }\end{array}$ \\
\hline $\begin{array}{l}\text { Comentários } \\
\text { dos internautas }\end{array}$ & $\begin{array}{l}\text { Elogios, indicação de } \\
\text { outros blogs, outros livros, } \\
\text { etc. }\end{array}$ & $\begin{array}{c}\text { Elogios aos livros, aos blogs, } \\
\text { postagens de outros livros, } \\
\text { etc. }\end{array}$ & $\begin{array}{c}\text { Elogios, dúvidas sobre } \\
\text { download das histórias, } \\
\text { alguma informação contraria, } \\
\text { etc. }\end{array}$ & Só no chat do blog & $\begin{array}{c}\text { Elogios das resenhas e do } \\
\text { blog }\end{array}$ \\
\hline Feedback & $\begin{array}{l}\text { Quando respondido é } \\
\text { tardio. }\end{array}$ & Rápido e preciso. & Aparentemente rápidos. & Não tem & Rápido e preciso \\
\hline
\end{tabular}

Fonte: Elaborado pela autora, 2016. 
Em relação à categoria da arquitetura dos blogs, foi observado que dos cinco blogs analisados, apenas um tinha a sua arquitetura complexa, ou falha, apresentando certa dificuldade na pesquisa e leitura do material.

Quanto ao layout, dois blogs apresentam um layout insatisfatório, com uma apresentação escura, informações que deveriam estar visíveis, não aparecem, tornando a página não muito atrativa para os usuários, prova disso é a pequena quantidade de seguidores e visitação nesses blogs.

As atualizações desses blogs são frequentes, com exceção de um deles que sua última postagem foi realizada em 10/05/2015. Nesse momento, vemos a importância da atualização para a sua continuidade. Um blog atualizado é um blog com grande número de visitação e frequentado por usuários interessados no tema.

Os assuntos apresentados nos blogs são na maioria de literatura romântica/erótica, com exceção do blog papo do homem que fala assuntos diversos, devido a amplitude alcançada, mas mesmo assim, ainda é considerado um blog adequado ao universo selecionado. Os conteúdos postados nesse blog são feitos tanto pelo público masculino quanto feminino que juntos trabalham para alcançar o sucesso.

Nos blogs analisados, não foram encontradas nenhuma informação acessível a um usuário com alguma necessidade especial, ou seja, esses blogs, não foram pensados para usuários especiais. Podemos citar como exemplo que limita o acesso à informação, blogs com telas escuras, letras muito pequenas, informações difíceis de encontrar, entre outras.

Quanto às visitas, os blogs são bem frequentados com exceção de dois deles, pois um não mostra a quantidade de usuários visitantes e outro a quantidade é muito pequena, já que o mesmo é desatualizado como já foi citado. A quantidade de seguidores é enorme nos blogs atualizados, pois quanto mais a informação é atual, mas esse blog será frequentado e consequentemente selecionado pelo usuário para participar do mesmo.

Os blogs de literatura erótica, em sua maioria, são de autoria feminina, mas em meio a essas comunidades de blogs, encontramos também autores masculinos. Eles postam basicamente as mesmas coisas que as mulheres, como resenhas, contos, dicas de outros livros; enquanto que no blog de autoria masculino analisado, tem postagens de artigos, mas também de dicas de leituras eróticas. Lembrando que nos blogs de literatura erótica escrita por mulheres, as leituras são mais interessantes, 
pela forma como as resenhas são mostradas, e logo, se tornam mais atrativos visualmente.

Em relação aos comentários, observou-se que os usuários fazem elogios, complementam alguma informação, fornecem indicação de outros livros e blogs relacionados ao tema. A seguir, destacam-se alguns comentários extraídos dos blogs visitados:

"Como não tinha visto esse blog antes, gente? Amei!!

"Livrinho fofo. Mocinho, apesar de libertino, quando se apaixona faz de tudo pela mocinha. Mocinha inocente, mas igualmente decidida. E ainda tem um marquês coadjuvante que aiai (suspiros). "

"Os contos são bons."

"Que legal, adorei as dicas, os esclarecimentos e curto muito o blog. Eu sou fã de muitos gêneros, mas o New Adulto acho que acabei de descobrir que é meu preferido rrrss. Parabéns pelo blog".

"Teve uma época do meu casamento que estava me sentindo muito mal, me sentia feia e pensei que tinha que mudar. Eu me maquiei toda, me produzi bem sexy e tirei várias fotos minhas sensuais, que por sinal ficaram lindíssimas, eu nem acreditei que era eu que estava ali...meu marido ficou louco e foi muito bom para minha autoestima... super indico!!”

"Esses livros fizeram uma verdadeira revolução na minha vida sexual e não tenho vergonha de mostrar a capa do livro como já vi por aí ou comentar a respeito e estimular minhas amigas a lê-los. Obviamente não é só isso, há muito mais envolvido, mas ler com a cabeça aberta, sem barreiras, o pensamento e a imaginação rolando solta, não tem erro. "

Também é possível observar a diferença de linguagem usada entre os homens e as mulheres que participam desses comentários, as mulheres além de fazerem elogios, também são mais sensíveis no que escrevem, enquanto os homens têm uma visão mais sexual da relação.

O feedback desses blogs é considerado bom, já que dos que foram analisados apenas em um não consta o retorno dos blogueiros para com seus seguidores e outro tem um retorno mais demorado; enquanto os outros três blogs, dos cinco pesquisados, têm um retorno excelente de resposta para com seus seguidores.

Através das perspectivas dos dados analisados, pode-se observar que o público desses blogs é de maioria feminina e adulta. Esses blogs suprem as 
necessidades informacionais do seu usuário em relação ao tema desejado, são blogs com boa atualização, com layout personalizado e simples entre outros. Além disso, de forma geral são bem frequentados e com um grande número de seguidores e visitantes, proporcionando assim o crescimento cada vez maior.

\section{CONSIDERAÇÕES FINAIS}

Durante as pesquisas realizadas, observaram-se mudanças ocorridas ao longo dos tempos em relação aos blogs. O blog começou como um diário íntimo, tornando-se público. Hoje, vem sendo usado não só para a divulgação da vida pessoal, mas para divulgar informações e interagir com seus usuários, que os seguem e apreciam os conteúdos explicitados neles.

Os blogs são evoluções resultantes dos diários pessoais, disponibilizados na web. Sendo dinâmicos e passíveis de publicações e gerenciamento por parte do seu administrador (blogueiro). Suas atualizações são parecidas com e-mails enviados, sem a necessidade de organização do conteúdo, já que estes podem ocorrer na maioria das vezes de forma automática.

Esta ferramenta não é restrita a pessoas físicas, podem ser institucionais, corporativos, temáticos, comunitários entre outros. Foi com essa proposta do blog temático que as mulheres resolveram participar e compartilhar seus pensamentos e fantasias, expondo suas ideias de forma não restrita. Se incorporando e adaptando este universo ao seu mundo.

Aproveitando uma oportunidade que antes não tinham, a literatura erótica inserida nos blogs foi um momento importante para o universo feminino já que estas eram proibidas de ler e escrever. Através de movimentos e lutas, conquistaram o direito ao voto (sendo uma das passagens mais importantes da história da política da mulher brasileira), o direito à educação, de se profissionalizar e de expor seus pensamentos sem restrições.

Estas tinham seus preceitos, conquistaram seu espaço e nos dias de hoje, elas se mostram de forma decidida a discutir seus direitos e deveres, sem medo da repressão e confiantes em tratar de temas que geram tanta polêmica como o erotismo. Como afirma Del Priore (2014) as mulheres eram completamente ignorantes em matéria de vida, pois, para serem puras tinham que ser literalmente ignorantes. 
Estas identificaram-se com as literaturas românticas, com o erotismo entrelaçado no meio das histórias, surgindo assim o gosto cada vez mais aguçado pela literatura erótica e sua divulgação nos blogs específicos do tema, pois dependendo do gênero ainda há muitos preconceitos.

Portanto, a proposta da literatura erótica é satisfazer a curiosidade do usuário ou propiciar uma reflexão a respeito desse tema. Entendendo melhor seu próprio corpo, seus desejos e prazeres desse liberalismo que se encontra guardado em cada um de nós.

Para alcançar o objetivo de analisar o universo feminino nos blogs de literatura erótica, foram selecionados cinco blogs com essa temática.

Em relação às análises dos dados da pesquisa, compreende-se que os objetivos foram alcançados, no sentido que mostra como os blogs de literatura erótica são apresentados, no que se refere ao universo feminino.

Verificou-se também através desses resultados que para o sucesso de um blog, este deve ser atualizado, já que o motivo que leva os blogs a serem desatualizados são falhas humanas, pois estes, necessitam do interesse de seus blogueiros, para alimentar as informações periodicamente.

Nesta perspectiva, os blogs literários eróticos foram criados, para que cada blogueiro possa expor suas ideias, fantasias e necessidades de expressar para o público o que pensam ou o que desejam. É através desses blogs de conteúdo erótico que visualizamos o universo feminino e como elas se portam em relação à literatura erótica e ao erotismo em geral. Através de comentários, elogios e dicas relacionados ao blog e aos temas expostos pelos blogueiros.

Quanto às análises das categorias, pode-se observar que dos cinco blogs analisados apenas um não tem uma arquitetura simples. Quanto ao layout, dois blogs apresentaram-se de forma insatisfatória, no entanto, apenas um é desatualizado; todos falam sobre literatura romance/erótica, mas não são acessíveis a todos os usuários, tendo em vista a falta de alternativas em relação a leitura por usuários com baixa visão, por exemplo. Em relação às visitas e aos seguidores observa-se que quanto mais atualizado é o blog, mais visitas e seguidores este possui. A maioria dos blogs de literatura erótica tem sua autoria feminina, as postagens e comentários são todos compatíveis com esse público e quanto ao feedback dos blogs analisados, três deles dão o retorno desejado aos seus usuários e, os outros dois, um deles não 
fornece nenhum retorno aos seus seguidores e um outro tem um feedback muito tardio.

Diante disso, este estudo tem enquanto relevância acadêmica e social, o intuito de desmistificar estigmas e estereótipos acerca da literatura erótica, sobretudo no que se refere a fontes de conhecimento e aprendizado. Antes de julgarmos esse gênero literário de forma tão negativa, primeiramente temos que conhecê-los, sentir a sua essência, para que através do conhecimento prévio, seja necessário favorecer o entendimento, as interpretações e principalmente a separação entre o erótico e o pornográfico, a fim de uma leitura mais prazerosa e social, despertando assim a imaginação e o prazer dos leitores.

Desta forma, fomenta a visibilidade agregando valor na contribuição técnicocientífico para a comunidade acadêmica, através da fonte de informação blog com perspectiva na literatura erótica e na evolução do universo feminino neste território digital.

A proposta é tratar a literatura erótica com novos olhares e novas perspectivas, visto que este é um assunto que a cada dia vem sendo abordado com mais frequência, resistindo aos preconceitos e provocando reflexões do que vem a ser conservadorismo e liberalismo quando o assunto é o gênero feminino em sua essência, beleza e atitudes.

Portanto, a perspectiva final desta pesquisa é possibilitar que essas obras passem a ser enxergadas como uma literatura comum, que o contato com essa literatura não classifique o indivíduo como uma pessoa sem pudores, arriscando sua reputação, pois os tabus que norteiam essas obras literárias são simplesmente por falta de conhecimento. Considera-se oportuna a extensão da pesquisa, levando em consideração que este assunto ainda é pouco abordado, necessitando de estudos mais aprofundados relacionados ao tema.

\section{REFERÊNCIAS}

ALEXANDRIAN. História da Literatura Erótica. Rio de Janeiro: Rocco, 1993. 439 p. Tradução de: Ana Maria Scherer e José Laurêncio de Mello.

BATAILLE, Georges. O erotismo. Belo Horizonte: Autêntica, 2014. 339 p. Tradução de: Fernando Scheibe. 
BOCAYUVA, Helena. Erotismo à brasileira. Rio de Janeiro: Garamond, 2001. 144 p.

CAMPELLO, Bernadete Santos; CAMPOS, Carlita Maria. Fontes de informação especializada: características e utilização. Belo Horizonte: UFMG; PROED, 1988. 143 p. (Coleção Aprender).

CHAGURI, Jonathas de Paula; BERTOLLETI, Vanessa Alves; AZEVEDO, Mário Luiz Neves de. A internet como espaço virtual para o incentivo a literatura. In: SINAGEL Simpósio Nacional de Pesquisa em Estudos Literários. 1, 2009, Maringá. Anais... Maringá, 2009, p. 591-596.

CIPRIANI, Fábio. Blog corporativo. São Paulo: Novatec, 2006, p. 207.

DANIELS, Mark. Mitologia Grega. In: DANIELS, Mark. A história da mitologia grega: Para quem tem pressa. 2. ed. Rio de Janeiro: Valentina, 2016. Cap. 7. p. 110-111. Tradução de: Heloísa Leal.

DANTAS, Maria Nívia. O gênero blog: ação social e multimodalidade. 2005. 105 f. Dissertação (Mestrado) - Curso de Letras, Centro de Ciências Humanas, Letras e Artes, Universidade Federal do Rio Grande do Norte, Natal, 2005. Disponível em: <repositorio.ufrn.br/jspui/bitstream/123456789/16166/1/MariaND.pdf>. Acesso em: 28 maio 2016.

ENCONTROS BIBLI: Revista eletrônica de Biblioteconomia e Ciências da Informação. Florianópolis: UFCS, 2009. Semestral. Disponível em: $<$ https://periodicos.ufsc.br/index.php/eb/article/view/15182924.2009v14nesp1p129/19839>. Acesso em: 25 maio 2016.

JOÃO, Sidnei Maximo. O trabalho e o direito da mulher. Rio de Janeiro: Lumen Juris, 1997. $101 \mathrm{p}$.

LÁCIO, Ana Flor de. O erotismo na literatura. Disponível em:

<http://www.recantodasletras.com.br/artigos/2782381>. Acesso em: 15 maio 2016.

L.M., Rita. Leitura X Erotismo: os leitores estão preparados para essa combinação?

Disponível em: <http://lounge.obviousmag.org/entrelinhas/2014/01/leitura-X-erotismoos-leitores-estao-preparados-para-essa-combinacao.html>. Acesso em: 15 maio 2016.

NOVAES, Caio. A história dos blogs. 2007/2008. Disponível em:

<http://www.brogui.com/a-história-dos-blogs/>. Acesso em: 26 out. 2016.

SANTOS, E. C. S. A linguagem dos blogs. Um gênero textual emergente. Cadernos de linguagem e sociedade, Brasília, v.6, p. 94-105, 2003. Disponível em: <http://periodicos.unb.br/index.php/les/issue/view/153>. Acesso em: 26 maio 2016.

SCHITTINE, Denise. Blog: comunicação e escrita íntima na internet. Rio de Janeiro: Civilização Brasileira, 2004. 235 p. 